\title{
A nova gestão pública e as políticas de programação orçamentária do governo*
}

\section{Introdução}

A teoria do guardian-spender,${ }^{1}$ formulada por Aaron Wildavsky, tem definido a maneira de pensar da maioria dos cientistas políticos sobre a programação orçamentária governamental desde seu surgimento, em 1964 (Wildavsky, 1975; Green e Thompson, 1999). Wildavsky argumentou que os resultados orçamentários poderiam ser explicados (ou pelo menos analisados) concentrando-se nos efeitos recíprocos dos atores orçamentários desempenhando os papéis institucionais altamente estilizados de guardião (do erário público) e de gastador. Esta teoria comportamental provou ser suficientemente flexível para julgar as diferenças na performance orçamentária por meio de diferentes sistemas políticos (consultar estudos de Savoie, 1990; Heclo e Wildavsky, 1974; Wildavsky, 1986), assim como para explicar o impacto da reforma orçamentária e de ambientes econômicos divergentes em relação a políticas orçamentárias (Caiden e Wildavsky, 1974; Wildavsky, 1975). Referências aos guardians-spenders ${ }^{2}$ ainda ocupam lugar importante nas discussões sobre a programação orçamentária do governo na literatura acadêmica da ciência política e econômica (Campos e Pradhan, 1997), e foram aceitas como descrição convencional por grupos de profissionais da área governamental e de instituições internacionais (tais como a OCDE, o Banco Mundial e o FMI).

Este artigo aplica a teoria do guardian-spender de Wildavsky para analisar o impacto das reformas nas políticas orçamentárias da New Public Management - NPM (Nova Gestão Pública), e para testar o valor explicativo contínuo dessa teoria. É amplamente aceito que as reformas da NPM são explicitamente projetadas para transformar as normas, regras,

Joanne Kelly é chefe de pesquisa do Expenditures and Management Strategies Sector no Canadá.

John Wanna é professor da Head of School Politics and Public Policy na Austrália.

Contatos: kelly.joanne@ tbs-sct.gc.ca j.wanna@ mailbox.gu.edu.au

Traduzido por René Loncan Filh 
processos e objetivos da gestão orçamentária e financeira existentes (Tesouro da Nova Zelândia, 1987; Hood, 1991; Boston et al., 1991; Pollitt, 1993; OCDE, 1995; Thompson, 1998). Nosso objetivo é estudar como estas reformas podem impactar o equilíbrio de poder entre os guardiões e os gastadores em um dado cenário orçamentário. Este estudo inicial se focaliza em três temas altamente recorrentes que tipificam a agenda da reforma orçamentária e financeira da NPM: objetivos orçamentários e cultura reformulados, controles de gastos agregados centralizados, e gestões financeiras delegadas. Na busca destas reformas, a NPM procura estabelecer novas convenções orçamentárias baseadas em relações de agente-principal, técnicas incrementais de contabilidade e de programação orçamentária baseadas em resultados, e programação orçamentária de contrato-preço (alternativamente chamadas de concorrência oferecida). Perguntamos se estas reformas da NPM remodelam ou transformam os sistemas orçamentários a tal ponto que a teoria de guardian-spender tenha diminuído seu valor explicativo.

Nossa análise prossegue em quatro seções. A primeira reexamina elementos centrais do modelo de política orçamentária de Wildavsky, enfocando, especificamente, a dicotomia do guardian-spender, as ferramentas e estratégias do "jogo orçamentário" e o impacto da reforma orçamentária. Em segundo lugar, identificamos as principais categorias das reformas introduzidas pela NPM (OCDE, 1995:94-197; 1998) na gestão orçamentária e na gestão financeira. A terceira seção deste artigo examina o impacto destas reformas na política orçamentária, especificamente, nos papéis e funções institucionais propriamente ditos; nas ferramentas e estratégias disponíveis para ambos os conjuntos de atores orçamentários; e no equilíbrio do poder dentro de um sistema orçamentário. Finalmente, concluímos questionando a sustentabilidade continuada da teoria de guardian-spender dados os novos problemas causados pelas mudanças no ambiente orçamentário (tais como o recente surgimento do excedente orçamentário e as dificuldades políticas associadas com excedentes administrativos, mantendo-se, ao mesmo tempo, restrições fiscais).

A conclusão desta análise sugere que onde as reformas da NPM têm sido extensivamente adotadas, e a longo prazo, elas alteram o terreno dos sistemas orçamentários, estabelecendo arranjos orçamentários mais complexos do que os sugeridos pelo modelo de guardian-spender. Asreformas da NPM tendem a mudar os comportamentos orçamentários e, conseqüentemente, a alterar o equilíbrio do poder, favorecendo os guardiões. Estas reformas também mudam o papel orçamentário dos gastadores como atores do orçamento. Portanto, a tradicional dicotomia entre os guardiões racionalizadores e os gastadores maximizadores é difícil de se manter, já que surgem relações orçamentárias mais complexas que não estão de 
acordo com modelo de guardian-spender. Além disso, as reformas da $N P M$ também têm potencial para mudar tanto os locais de conflito orçamentário quanto as áreas de acordo. As relações orçamentárias têm tendência à fragmentação e à incerteza, e a se tornarem menos rotineiras se os prestadores de serviços contratuais são incluídos no processo. O conflito tem tendência a dissipar-se para longe das agências centrais de orçamento, com gastadores assumindo papéis de guardiões com relação a recursos que eles mesmos poderiam escolher para distribuir na compra de serviços contratuais de outros atores. $\mathrm{O}$ advento de orçamentos plurianuais (proporcionando autorizações para dois ou três anos) também tem potencial para conter conflitos orçamentários. Finalmente, perguntamos se as "transformações" para os sistemas orçamentários da NPM poderiam requerer novas emendas, já que os governos têm, freqüentemente, que gerenciar excedentes orçamentários.

\section{Estratégias e ferramentas das políticas orçamentárias}

Em The New Politics of the Budgeta ry Process (As Novas Políticas do Processo Orçamentário), Aaron Wildavsky estabeleceu novos métodos de investigação nos processos de programação orçamentária do governo (Jones e McCaffery, 1994). Mais do que prosseguir de uma base normativa que procurava definir como o governo deveria orçar, Wildavsky concentrou-se em explicar "como o processo orçamentário realmente funciona" (1974: 25). Ele revelou a natureza altamente competitiva, mas incerta, da formulação orçamentária, a complexidade inerente das decisões orçamentárias, e como os atores orçamentários precisam especializar-se, "satisfazer-se" e confiar na "heurística das decisões" para conter conflitos. Normas comportamentais tendiam a caracterizar as programações orçamentárias do governo na ausência de procedimentos formais para o controle financeiro. Em outras palavras, Wildavsky construiu um quadro para o estudo das políticas das programações orçamentárias do governo que destacava três elementos primordiais das políticas orçamentárias:

- as relações dicotômicas entre os guardiões e os gastadores tornaram-se pronunciadas na ausência de regras e de procedimentos formais de controle financeiro;

- estratégias e práticas dos atores proporcionaram um certo tipo de "rotina" para as políticas orçamentárias; e

- o impacto da reforma nas políticas orçamentárias tendia a ser limitado.

As políticas orçamentárias do governo são descritas como um jogo entre dois conjuntos de atores que desempenham os papéis institucionais 
de guardiões e de gastadores. Wildavsky classificou os protagonistas orçamentários de acordo com critérios fracamente definidos e altamente estilizados, baseados na "expectativa de comportamento vinculada a posições institucionais” (1975:11). Estes papéis são desempenhados a cada estágio do processo orçamentário e em todos os níveis da esfera política e burocrática. Wildavsky resumiu seu argumento da seguinte forma:

"Uma das constantes das programações orçamentárias é a divisão de papéis entre gastadores e poupadores, como resultado da escassez universal de recursos. As reivindicações e as demandas sempre superam os recursos para satisfazê-las. Por isso, sempre há pessoas que querem mais do que têm, e outras que lhes mostram que elas não podem ter tudo que gostariam. Os funcionários encarregados de promover as funções do governo são orientados na direção das necessidades. Eles estão sempre sendo confrontados com coisas que não estão sendo feitas, mas que deveriam ser. Eles desempenham melhor suas tarefas quando defendem essas necessidades. Por este motivo, o erário público precisa de guardiões que assegurem que o gasto não ultrapasse os recursos disponíveis e que todas as despesas assumidas recebam uma parte do que está disponível" (Wildavsky, 1975:187).

Embora Wildavsky tenha reconhecido que a dicotomia entre os gastadores e os guardiões resultou em um conflito de adversários, ele não definiu este conflito como problemático. Um programa orçamentário bemsucedido é retratado como um produto das relações correntes entre guardião e gastador: ambos os papéis são legítimos e necessários na resolução de decisões orçamentárias. Dividir funções e responsabilidades entre os gastadores e os guardiões viabiliza a especialização, aumenta a previsibilidade e, portanto, reduz a complexidade na tomada de decisões orçamentárias. Os programas são gerados por aqueles que têm conhecimento especializado; os limites entre receita e despesa são estabelecidos pelos responsáveis pelo desempenho econômico e fiscal do governo. A interação entre esses dois lados reforça o compromisso e exige que ambos justifiquem e defendam suas posições: a especialização e os conflitos institucionais entre gastadores e guardiões produzem orçamentos melhores.

Em segundo lugar, os guardians-spenders empregam uma gama de estratégias, práticas e procedimentos para ampliar seus objetivos em negociações orçamentárias, e essas "técnicas de competição" são conhecidas. Todos os sistemas orçamentários fornecem opções limitadas aos atores, e em resposta eles idealizam um conjunto de estratégias e de práticas usadas para participar do “jogo orçamentário". Na tentativa de "proteger o erário público" dos gastadores, os guardiões podem evocar sua 
autoridade legislativa e administrativa, tentar exercer uma persuasão "moral", ou então gerenciar procedimentos de tomada de decisões do orçamento. No parlamento e no congresso, os guardiões têm autoridade legal para reduzir, ou simplesmente negar, o financiamento requerido por uma agência específica. As agências centrais do orçamento adaptam os sistemas de contabilidade financeira para controlar despesas. Os ministros guardiões podem ameaçar aumentar os níveis dos impostos ou impor cortes por meio de uma junta. Eles irão, com freqüência, buscar entendimentos nas metas de despesas ou em estratégias racionalistas, antes de prosseguir com negociações orçamentárias mais detalhadas. Por sua parte, os gastadores se retraem em sua posição de peritos de política ou de programa, para legitimar reivindicações, visando proteger despesas existentes, aumentar a parte que lhes cabe das despesas públicas ou para adicionar novos programas e expandir programas existentes. Não só devem os gastadores apresentar "bom trabalho" e "jogar de acordo com as regras", mas eles deveriam ser capazes de reconhecer e explorar oportunidades disponíveis no momento apropriado. A expertise política é baseada nas relações com a clientela do programa ou no conhecimento do serviço, mas, ainda assim, os gastadores devem tomar cuidado para não passar a imagem de serem "capturados" por estes clientes. Protegendo sua base corrente, os gastadores podem ameaçar queimar o "Monumento de Washington". Ambos os conjuntos de atores procuram dirigir sua influência política para a posição desejada, atraindo suporte ministerial ou do congresso, mobilizando grupos de interesse ou membros influentes do corpo administrativo. Ainda assim, as programações orçamentárias não são uma "luta livre" entre os guardiões e os gastadores: os atores orçamentários tanto cooperam quanto competem entre si. A complexidade da tomada de decisões no orçamento requer áreas de estabilidade e técnicas de limitação ou confinamento de conflitos. Por exemplo, ao determinar quanto de financiamento extra deve ser requerido ou quanto deve ser outorgado, os atores do orçamento devem confiar em várias “ajudas de cálculo”. No sistema descrito por Wildavsky, ambas as partes devem se basear em experiências passadas como um guia, tanto para a confiabilidade das demandas de um departamento quanto para a possibilidade de gastos serem aprovados. Eles simplificam as questões em consideração, limitando o foco das discussões às informações em vez de às políticas, ou excluindo certos grupos de despesas sobre as quais já se havia concordado - como aqueles incluídos na "base" ou as despesas não discricionárias — das negociações orçamentárias. Como resultado, os tomadores de decisões do orçamento tendem a "satisfazer-se", em vez de rever, de forma compreensível, cada uma das opções possíveis. O método de incremento das programações orçamentárias implica em mudanças anuais regulares de despesas 
(tipicamente aumentos) em todas as áreas de despesas de cada departamento. Os gastadores sabem que eles terão uma "parte justa" de aumento; os guardiões sabem que os aumentos não serão muito elevados. As perdas de um ano podem ser recuperadas em outro ano; os problemas de um ano podem ser adiados até o próximo. Wildavsky conclui: "os homens que fazem o orçamento estão preocupados com incrementos relativamente pequenos de uma base existente. A sua atenção está concentrada em um pequeno número de itens em função dos quais a batalha orçamentária é travada" (1974:15).

Terceiro, a reforma orçamentária certamente irá alterar o equilíbrio de poder entre os guardiões e os gastadores, e assim afetar os resultados orçamentários. Isto acontece porque as estratégias atuais disponíveis aos atores orçamentários varia de acordo com o sistema político, econômico e orçamentário dentro do qual o “jogo” orçamentário ocorre. O equilíbrio de poder, ao longo do tempo, é amplamente dependente, na medida em que, no confronto entre guardiões e gastadores, ambos são capazes de tirar vantagens dessas estratégias. Sob condições institucionais, políticas e econômicas estáveis, o jogo da política orçamentária se transforma em rotina: cada jogador sabe o que esperar do outro, e "os participantes têm papéis opostos que necessitam de um forte empurrão por parte do departamento" (Wildavsky, 1974:19). A reforma orçamentária altera este equilíbrio e acordos prévios entre as áreas de política orçamentária se tornam altamente contestáveis. Esta é uma das maiores razões por que a reforma orçamentária é fortemente política, ameaçadora e ardentemente contestada.

É dentro deste contexto que nós analisamos as reformas orçamentárias introduzidas sob os auspícios da NPM. As principais reformas associadas à $N P M$ foram desenhadas precisamente para mudar a maneira pela qual os recursos públicos são alocados e gerenciados. Desta maneira, a NPM tentou reconstruir várias das tradicionais "ferramentas da política orçamentária". Na medida em que é bem-sucedida neste ponto, é provável que a $N P M$ impacte os papéis e a capacidade dos principais atores orçamentários. As seções restantes deste artigo apresentam um estudo preliminar do que a NPM procura atingir nesta reforma orçamentária; o que o paradigma básico define como "boa" prática orçamentária; como estas novas práticas orçamentárias e gestão de recursos têm impacto nos guardians-spenders; e como as reformas da NPM têm impacto no conflito orçamentário. 


\section{A NPM e a visão de "melhores programações orçamentárias"}

O núcleo central das reformas da $N P M$ tem, até hoje, sido dirigido para a reconstrução da natureza da provisão pública, usando, principalmente, uma gestão financeira e de recursos melhorada. Até meados dos anos 70, muito havia sido escrito sobre os problemas das programações orçamentárias tradicionais (Wilenski, 1986: 225). Estudos sobre os sistemas de programações orçamentárias norte-americanos e britânicos sugerem que os processos orçamentários clássicos favoreciam os gastadores em relação aos guardiões, e eram causadores de impostos, dívidas e déficits sempre crescentes. Estas críticas repercutiam das comissões de inquérito para sistemas tradicionais de administração pública estabelecidos por governos do mundo todo. Estas incluíam as comissões de Glassco (1962) e de Lambert (1976-9) no Canadá, os relatórios de Coombs (1974-6) e de Reid (1982-3) na Austrália, e a Comissão Grace de Reagan, estabelecida em 1982. No Reino Unido, Thatcher estabeleceu a Efficiency Scrutiny Unit (Unidade de Escrutínio de Eficiência ), no começo dos anos 80, para conduzir "escrutínios" regulares da eficiência e da economia na administração departamental. Cada uma destas investigações apresentou uma série de reclamações contra sistemas orçamentários tradicionais e contra as técnicas financeiras obsoletas usadas dentro do governo. Elas recomendaram, ao invés disso, a adoção de reformas de longo prazo normalmente dirigidas no sentido de "deixar os gerentes gerenciarem" - encorajando uma flexibilidade gerencial dentro de uma linha de trabalho de objetivos definidos, controles rígidos de recursos e monitoramento de desempenho.

Ainda assim, cada inquérito defendeu formas variadas de reformas da gestão financeira e orçamentária, e muitas de suas detalhadas recomendações aparentavam ser contraditórias. Por um lado, os críticos argumentavam que o orçamento tradicional provia os guardiões com autoridade insuficiente ou com incentivo insuficiente para limitar pedidos de despesas aumentadas por departamentos de linha. As agências centrais pareciam ser altamente incapazes de superar as tendências incrementais inerentes ao processo orçamentário tradicional, e faltavam incentivos que iriam encorajá-los a achar novas maneiras de fazê-lo. Se aos governos cabia limitar o tamanho e o crescimento das despesas públicas, então seriam necessárias reformas que fortificassem a posição dos guardiões do orçamento. Por outro lado, as regras orçamentárias tradicionais e os controles financeiros eram criticados como sendo demasiado restritivos e voltados para o controle, de modo a permitir uma gestão financeira eficiente e efetiva (ver Schick, 1994; 1997). Os processos orçamentários eram orientados para informações de medida, encorajando os administradores a focalizar-se em regras de probidade e em "contagem de grãos", em vez 
de se concentrarem em resultados, na eficiência ou na efetividade dos programas governamentais. De acordo com os reformistas da NPM, os novos sistemas orçamentários deveriam ser projetados para permitir flexibilidade e aumentar a responsabilidade dos gerentes, em ambos os casos, racionalizando recursos e operando dentro daqueles limites (Dawkins, 1983:3).

Em sua grande maioria, estas contradições provinham de diferenças entre as New Institutional Economics - NIE (Novas Economias Institucionais) e o "gerencialismo" — as primeiras armações intelectuais de referência que davam informações sobre estas análises (Aucoin, 1990; Hood, 1991; Pollitt, 1993; Hughes, 1994; Keraudren e Van Mierlo, 1998:39). Novos economistas institucionais, que aplicam suas idéias ao setor público, identificaram um comportamento "perverso" nas instituições orçamentárias tradicionais, causando ineficiência tanto em níveis agregados quanto em nível departamental (para uma revisão detalhada, ver Thompson, 1998). Orçamentos tradicionais agregavam as escolhas individuais de atores orçamentários que buscavam, cada um, seus próprios interesses. Isto produziu decisões de despesas "subotimizadas" (que resultam em gastos acima dos níveis ideais e em déficits e dívidas indesejados) porque o custo de programas governamentais, cada vez mais numerosos, pode ser exteriorizado em um sistema no qual as rendas são geradas por impostos largamente baseados e distribuídos por fundos de renda consolidados. Em outras palavras, os beneficiários dos programas governamentais não agüentam o imposto pleno ou os custos políticos de aumento de despesas. Os benefícios são bastante concentrados enquanto que os custos são pagos pela população pagadora de impostos. Além disso, os sistemas de custos dos programas governamentais deram pouca atenção às transações ou custos das agências para conduzir os negócios internos do governo ou prestar serviços. Portanto, na NIE, as ações coletivas de atores orçamentários individuais, comportando-se de forma racional no processo orçamentário, resultarão em níveis totais de despesas mais altos do que aqueles considerados como resultado coletivo ótimo.

Em resposta, a NIE promoveu uma reforma institucional para estabelecer diferentes modelos de incentivo na gestão dos recursos governamentais. As reformas orçamentárias, sustentavam eles, deveriam estabelecer regras e instituições que promovessem objetivos "coletivamente racionais", a serem articulados e perseguidos na formulação orçamentária. Para este fim, os níveis totais de despesas deveriam ser centralmente determinados e depois usados para disciplinar as negociações orçamentárias subseqüentes (Von Hagen, 1992; Alesina e Perrotti, 1997). Tais determinações são difíceis do ponto de vista dos sistemas de tomada de decisões colegiada, que caracterizavam os processos orçamentários tradicionais, e, assim, deveriam ser substituídos por níveis hierárquicos superiores 
de tomadas de decisões. As reformas de gestão financeira deveriam redesenhar as estruturas de incentivo para alinhar o interesse próprio dos gerentes com as intenções coletivas. Instituir prestação de serviços competitiva, baseada no mercado, e técnicas de colocação de preços, pode fazer baixar os custos dessa prestação de serviços. E a insistência na distinção entre as funções operacionais e de política do governo (principal-agent) purchaser-provider split) diminui os custos de transação associados à procura e captação de recursos pelos departamentos (Tesouro da Nova Zelândia, 1987:44-8, 72-95).

Em contraste, o gerencialismo identificou as regras existentes e as práticas de administração pública como uma fonte de ineficiência governamental (Pollitt, 1993). Foi dito que os valores da administração pública tradicional enfatizavam a probidade e a condescendência em detrimento da eficiência e da economia. Como conseqüência, os burocratas de ambas as agências, gastadora e guardiã, "administravam" regras e regulamentos, em vez de "gerenciar" seu programa e seus recursos de política. O gerencialismo propunha que estes problemas poderiam ser resolvidos com a adoção de técnicas de gerenciamento do setor privado, melhorando a qualidade, o status e a contabilidade do gerenciamento operacional. A responsabilidade por um programa orçamentário detalhado e pela gestão financeira deveria caber aos responsáveis pelos programas governamentais. Apropriações detalhadas deveriam ser substituídas por dotações mais abrangentes, definidas pelos objetivos do programa. Fortemente associada à delegação de autoridade, encontra-se o gerenciamento de risco e a desregulamentação de técnicas de gestão financeira e sistemas de controle baseados em processos. Os gerentes de linha deveriam estar livres de "regras ou restrições triviais" (Pollitt, 1997:467) e assim poderem ser capazes de transferir recursos como melhor lhes parecesse. As regras sobre os modos de prestação de serviços também deveriam ser reduzidas para possibilitar que os gerentes de programas tivessem mais liberdade de ação para conseguir "maior aproveitamento com menos gastos". Os objetivos dos programas deveriam ser claramente articulados, assim como deveria haver ligação entre a avaliação do programa e as alocações orçamentárias. Em suma, as reformas procuram construir um setor público no qual “os gerentes não estão limitados, como no orçamento de linha/item, as despesas de uma informação em particular, mas que possam, conforme as circunstâncias mudam, julgar a composição correta de recursos ou de informações que irão promover, da melhor forma possível, o sucesso do programa" (Wilenski, 1986: 231).

Os governos-membros da OCDE adotaram estas recomendações de forma variada. Três principais categorias de reforma foram introduzidas: a reformulação do ambiente orçamentário; a centralização dos controles 
de despesas agregados e a delegação da responsabilidade para um gerenciamento detalhado dos recursos (OCDE, 1995; 1997). Cada uma delas pode ser justificada por qualquer um dos quadros sustentados pelo paradigma da $N P M$. A reformulação do ambiente orçamentário redireciona o interesse próprio dos burocratas e dos políticos, e proporciona gerentes com objetivos claros para os quais eles devem direcionar sua atenção. Controles de despesas agregadas, centralizados, proporcionam aos gerentes um ambiente de planejamento estável, e meios para limitar o consumo dos recursos públicos. A delegação de responsabilidade para o gerenciamento detalhado de recursos aumenta a flexibilidade e força dos gerentes a assumir responsabilidade pelas despesas governamentais (assim internalizando os custos das despesas públicas). Na seção seguinte, exploramos tanto os impactos esperados quanto os não antecipáveis dessas categorias de reforma no papel e na capacidade dos gastadores e dos guardiões no processo orçamentário.

Antes de proceder esta análise, é importante reconhecer a variação e a evolução contínua das reformas da NPM em diferentes países (Aucoin, 1990; Forster e Wanna, 1990; Hood, 1994; Kettle, 1997; Pallott, 1998; Peters e Savoie, 1998; Verheijen e Coombes, 1998). Estudos comparativos e individuais de alguns países mostram variação considerável na maneira que estas duas estruturas teóricas informam a NPM. Por meio de um breve resumo, a Tabela 1 identifica algumas das principais declarações e articulações da NPM nos cinco países anglo-americanos e (baseando-se na literatura existente) demonstra quais são os "parceiros" da NPM que dominam a agenda de reformas em cada país. Em várias instâncias, o sustentáculo teórico permaneceu implícito. A auto-identificação da Nova Zelândia com a NIE é a exceção (Tesouro da Nova Zelândia, 1987; Boston, 1993). Existe, é claro, muita superposição entre as duas estruturas, e esta simples classificação ignora os processos de aprendizado e interação entre nações, por meio dos quais o paradigma da NPM evoluiu (como exemplo, ver Auditor-Geral Canadense, 1995; Nagel, 1997). No entanto, estas diferenças destacam uma qualificação importante para os argumentos apresentados abaixo: o impacto da $N P M$ nas políticas orçamentárias vai variar entre os países. As seções seguintes deverão ser lidas com esta qualificação em mente. 
Tabela 1: Manifestos e marcos selecionados da NPM

\begin{tabular}{|c|c|c|}
\hline País & Manifesto(s) e marcos (ano) & Influência dominante \\
\hline \multirow[t]{2}{*}{ Reino Unido } & $\begin{array}{l}\text { Pesquisa de Rayner (1979); Melhorias } \\
\text { da Administração Financeira (1982 } \\
\text { CMND 9058, 1983); Melhorias da } \\
\text { Administração no Governo: os Pró- } \\
\text { ximos Passos (The next steps) (Unidade } \\
\text { de Eficiência, 1988). }\end{array}$ & $\begin{array}{l}\text { "Gerencialismo" (Kemp, } \\
\text { 1990; Hood, 1991; } \\
\text { Pollitt, 1993). }\end{array}$ \\
\hline & A Modernização do Governo (1998). & $\begin{array}{l}\text { Governo coordenado - } \\
\text { unido. }\end{array}$ \\
\hline \multirow[t]{2}{*}{ Austrália } & $\begin{array}{l}\text { Comissão Real sobre a Administração } \\
\text { Governamental Australiana (1976); O } \\
\text { "Relatório de Reid" (1983); Refor- } \\
\text { mando o Serviço Público Australiano } \\
\text { (1983); FMIP (1984); Reforma Orça- } \\
\text { mentária (1984); O Setor Público } \\
\text { Australiano Reformado (1992). }\end{array}$ & $\begin{array}{l}\text { "Gerencialismo" (Keating, } \\
\text { 1989; Hood, 1991; } \\
\text { Corbett, 1992; Davis et } \\
\text { al., 1999). }\end{array}$ \\
\hline & $\begin{array}{l}\text { Além da Contagem de Sementes: Admi- } \\
\text { nistração Financeira Efetiva na Admi- } \\
\text { nistração Pública Australiana } 1998 \text { e } \\
\text { Além (1997); Esclarecendo a Troca: } \\
\text { Uma Revisão dos Arranjos de Compra- } \\
\text { dor/Provedor. Comissão Nacional de } \\
\text { Auditoria (1996). }\end{array}$ & $\begin{array}{l}\text { Nova Economia Insti- } \\
\text { tucional - contratua- } \\
\text { lismo, contestabilidade. }\end{array}$ \\
\hline Nova Zelândia & $\begin{array}{l}\text { Administração Econômica (1984); } \\
\text { Declaração da Revisão das Despesas do } \\
\text { Governo (1986). } \\
\text { Administração Governamental: Resumo } \\
\text { do Governo Recém-eleito (1987). }\end{array}$ & $\begin{array}{l}\text { Nova Economia Institu- } \\
\text { cional - esp. Teoria da } \\
\text { Escolha Pública (Boston et } \\
\text { al., 1991:2-26; Pallott, } \\
\text { 1997). }\end{array}$ \\
\hline Estados Unidos & $\begin{array}{l}\text { Estudo do Setor Privado do Presidente } \\
\text { sobre o Controle de Custos (Comissão } \\
\text { Grace, 1982). } \\
\text { Reinventando o Governo (1992); } \\
\text { Revisão do Desempenho Nacional } \\
\text { (1993). }\end{array}$ & $\begin{array}{l}\text { "Gerencialismo" } \\
\text { (Pollitt, 1993; Kettle, } \\
\text { 1997; Thompson, 1998; } \\
\text { Frederickson, 1996). }\end{array}$ \\
\hline \multirow[t]{2}{*}{ Canadá } & $\begin{array}{l}\text { Relatório do Auditor-Geral sobre a } \\
\text { Administração Financeira (1978). } \\
\text { Comissão Real sobre a Administração } \\
\text { Financeira e a Contabilidade - } \\
\text { O Relatório "Lambert" (1979); } \\
\text { O Aumento da Autoridade Ministerial e da } \\
\text { Contabilidade (1988); Serviço Público } \\
2000 \text { (1992). }\end{array}$ & $\begin{array}{l}\text { "Gerencialismo" (Aucoin, } \\
\text { 1990; Peters e Savoie, } \\
\text { 1998). }\end{array}$ \\
\hline & $\begin{array}{l}\text { Getting Government Right (1995); A } \\
\text { Controladoria Moderna; Quebrando } \\
\text { Barreiras no Serviço Público Federal. } \\
\text { Em direção à Melhor Governança: } \\
\text { A Reforma do Serviço Público na Nova } \\
\text { Zelândia (1984-94) e sua Relevância } \\
\text { para o Canadá (Auditor-Geral, 1995). }\end{array}$ & $\begin{array}{l}\text { Nova Economia } \\
\text { Institucional. }\end{array}$ \\
\hline
\end{tabular}




\section{Reformulação da cultura e dos objetivos orçamentários}

Uma das forças motrizes da agenda da $N P M$ é o esforço para mudar os objetivos e a cultura das programações orçamentárias do governo. O surgimento da $N P M$ na maioria dos países, durante os anos 80 , coincidiu com o começo de uma era que enfatizava a restrição e a retidão fiscal. A maioria dos "Manifestos e Marcos" da NPM identificaram, na Tabela 1, as atuais reformas da gestão financeira como uma solução para os problemas da ineficiência do setor público, um setor público grande demais e níveis insustentáveis de dívidas do governo, ou as três alternativas. O orçamento tradicional, alega-se, contribuiu para o aumento das despesas do governo, enfatizando o planejamento, mais do que restringindo, e sua dependência para com um incremento na tomada de decisões. Similarmente, os sistemas de gestão financeira baseados no controle foram projetados para garantir a probidade nas despesas do governo e, por diversas vezes, impediram a busca de economia, de eficiência, e de efetividade na prestação de serviços. Em contraste, as reformas da NPM procuraram estabelecer os valores da economia e da parcimônia (Hood, 1991); encorajar os gerentes a "fazer mais com menos"; a "restringir o Leviatã"(caos); e ofereceram um meio de "evitar que o setor público exija uma parcela cada vez maior dos recursos nacionais" (OCDE, 1995:94). Em outras palavras, as reformas da NPM procuram introduzir uma mudança cultural que enfatiza os objetivos normalmente associados à proteção, em vez daqueles associados ao gasto.

Esta mudança na ênfase afeta as políticas orçamentárias em diferentes níveis. Primeiramente, ela deslegitima o debate sobre como se deve gastar o dinheiro do governo, enfatizando a importância dos cortes de despesas e das restrições. A ênfase do debate sobre o orçamento desviouse do desenvolvimento de políticas para as questões dos resultados financeiros "finais". Fazendo isto, ela reduziu a legitimidade dos gastadores nas redes de reformulação orçamentária. Segundo, ela proporcionou estratégias adicionais aos guardiões nos debates orçamentários: argumentos. Terceiro, ela limitou a capacidade dos gastadores de defender sua "porção justa" do aumento de despesas. Em um clima de aumento de despesas, os gastadores poderiam apresentar demandas para aumentar as despesas baseadas nos princípios de "reciprocidade" e de demanda pública. Em um clima de restrições, os gastadores que fizessem estas declarações corriam o risco de serem rotulados de rent-seekers ou de prisioneiros dos próprios interesses. Quarto, as demandas de restrição coletiva de despesas exigem que os gastadores assumam alguma responsabilidade na identificação de possíveis áreas de corte de despesas e de restrições. Exigia-se que os atores orçamentários nas instituições gastadoras 
"racionassem" e "economizassem" em vez de agir exclusivamente como demandadores. Finalmente, estes novos objetivos orçamentários estabeleceram um ambiente receptivo a futuras reformas direcionadas para a restrição de gastos. Isto fortaleceu a posição dos guardiões para moldar e desenhar as reformas em andamento do sistema de orçamento governamental e de gestão financeira.

\section{Políticas orçamentárias em controles de despesas centralizados}

Em 1995, a OCDE relatou que a maioria dos países-membros tinha estabelecido algum tipo de controle centralizado sobre os níveis de despesas agregadas (OCDE, 1995:95). Embora este relatório se concentre, principalmente, em declarações altamente visíveis de metas orçamentárias, os controles de gastos agregados variam de declarações de "metas orçamentárias de alto nível", políticas anuais mais específicas ou metas e limites de despesas específicos de certas pastas, até a adoção, pelas agências, de orçamentos plurianuais com verbas limitadas. Assim como variam no nível de detalhes, estas declarações variam na intenção. Algumas são dirigidas ao planejamento da taxa de crescimento das despesas do governo exemplos desses planejamentos totais ocorreram no Canadá (PEMS) e no Reino Unido (PESC), (Wright, 1980) — ; outras procuram introduzir uma tendência em direção a restrições de despesas, enquanto outras, ainda, são o ponto de partida para as negociações internas sobre orçamento. Estas declarações têm impacto direto e indireto nas relações entre os guardiões e os gastadores e seus papéis orçamentários. Declarações públicas dos objetivos orçamentários - especialmente aquelas com limites específicos de despesas plurianuais - restringem ambos, na medida em que qualquer um, gastador ou guardião, pode programar a agenda orçamentária. Por um lado, isto limita a capacidade de argumentar a favor de maiores níveis de despesas, ou a habilidade para aumentar os níveis totais de gastos, por meio de processos aditivos de baixo para cima. Mas uma declaração de metas orçamentárias também pode limitar a flexibilidade dos guardiões em programar os parâmetros orçamentários gerais, e também limitar a capacidade de responder a demandas de curto prazo, sejam elas econômicas ou políticas. A experiência, até a presente data, sugere que várias das declarações de alto nível sobre os objetivos orçamentários são programadas fora do processo orçamentário formal (durante campanhas eleitorais, por exemplo). Nestes casos, o objetivo primordial das negociações orçamentárias é determinar como fazer para atingir e permanecer dentro destas metas pré-estabelecidas, mais do que estabelecer as metas de despesas que deveriam ser atingidas. 
O cumprimento dessas metas de despesas estabelecidas nestes documentos requer mudanças tanto na organização quanto no procedimento orçamentário. Os planos orçamentários são projetados para assegurar as decisões sobre despesas agregadas anuais e as prioridades são programadas antes que comecem as decisões sobre alocações. Em alguns países, essas metas e limites específicos são decididos por um número muito pequeno de ministros guardiões e de funcionários, e deliberadamente excluem qualquer participação dos gastadores. Com frequiência, essas reformas são acompanhadas de limitações (ou são abolidas) do processo anual ordenado sobre despesas em programas continuados (as estimativas de adiamento da Austrália e o PESC britânico). As despesas de "base" são determinadas automaticamente, e a responsabilidade pela alocação de qualquer despesa adicional é delegada aos representantes mais antigos dos ministérios que realizam despesa (ministros, diretores, administradores de finanças). Estas reformas procuram excluir os gastadores dos debates sobre os agregados orçamentários e assim aumentar a autoridade dos guardiões.

$\mathrm{O}$ estabelecimento de controles de despesas agregadas fornece aos guardiões um ponto de referência externo para restringir os esforços de expansão das agências gastadoras, e para orientar o trabalho dentro da agência orçamentária. Um antigo chefe do Ministério das Finanças da Austrália uma vez afirmou: "não há nada que as Finanças ou o Tesouro amem mais do que limites de despesas publicamente declarados; isto provê uma arma com a qual eles podem arrasar os ministérios gastadores nas negociações do orçamento" (entrevista; Keating, 1998). A promoção do espírito de um orçamento corporativo no serviço público reduz a eficiência dos argumentos dos gastadores baseados em sua posição de advogados de grupos particulares de interesse. Tais argumentos tendem a resultar em uma acusação de rent-seeking em vez de realçar a validade das demandas gastadoras. Além disso, afirmações claras de quando e por que as despesas têm aumentado, ou as metas não foram atingidas, possibilitam que um público interessado culpe os "desperdiçadores". Estes processos têm mais tendência a atribuir os custos políticos dos aumentos de despesas aos gastadores do que aos guardiões.

Em suma, articular e desenvolver controles centralizados de despesas agregadas normalmente exige a introdução de processos orçamentários hierárquicos, ou de cima para baixo, que mudam a posição e as funções dos guardiões e dos gastadores. Várias destas reformas reduzem, deliberadamente, o acesso dos gastadores às tomadas de decisões nas despesas agregadas e na formulação do orçamento. Em termos de decisões de despesas mais detalhadas, exige-se que os gastadores desempenhem uma função de racionamento sobre as despesas pelas quais eles são 
responsáveis. Ao mesmo tempo, estas reformas aumentam as estratégias

e as ferramentas disponíveis aos guardiões no controle das demandas sobre o erário público, mas exigem que eles se empenhem em atividades orçamentárias bem diferentes das que eles costumam exercer. Os guardiões se concentram em assegurar que as metas finais sejam cumpridas, mais do que em se empenharem em negociações, com os gastadores, sobre níveis detalhados de despesas e de decisões de políticas.

\section{As políticas orçamentárias em um regime de gestão flexível de recursos}

As reformas da NPM são projetadas para aumentar a concentração da flexibilidade gerencial em dois temas principais: delegar a gestão financeira e introduzir novas formas de prestação de serviços. O primeiro aumenta a flexibilidade para gerenciar uma dada base de recursos, mesmo dentro de estruturas ministeriais tradicionais. Isto tem o objetivo de fazer com que a prestação de serviços do setor público seja mais eficiente, reduzindo os papéis "ineficientes" e os regulamentos que limitam a capacidade gerencial para melhorar a gestão de recursos. O segundo conjunto de reformas estende a noção de "flexibilidade gerencial", desafiando noções tradicionais de governo nas quais os ministérios são provedores exclusivos de serviços públicos. Este novo método de governo é baseado na implementação de uma divisão comprador/provedor e de métodos baseados no mercado de custos e preços (Ewart e Boston, 1993). Em vez de confiar na opinião de provedores de serviço internos, os governos procuram determinar o menor "preço de compra" de prestação de serviços por meio de concorrência, de um teste de mercado (market-testing), de sistemas de contabilidade de custos plenos. O governo, então, entra em uma relação contratual formal, tanto com provedores do setor privado quanto do setor público, para prestar o bem ou o serviço desejado a um preço dado. Em tese, isto permite que o governo consiga atingir preços menores, evitar a captura por clientes e reduzir os custos de transação. Embora os provedores do setor público possam "ganhar" contratos do governo, eles deveriam operar como unidades de comércio reconstituídas com base em fins lucrativos (ver trabalho sobre agenciamento de Pollitt, 1999) e "separado" do ministério ao qual estão vinculados. Neste modelo, um "ministério" governamental consiste em uma equipe de gerentes de política e de contratos. A adoção de qualquer um dos modelos de gestão "flexível" muda significativamente o papel e o relacionamento entre gastadores e guardiões.

A delegação da gestão financeira elimina algumas ferramentas tradicionais de guarda, e, ao mesmo tempo, exige que os gastadores assumam 
a responsabilidade de "racionar" os recursos públicos — uma função tradicionalmente associada com a guarda. A capacidade das agências centrais orçamentárias de impor controles financeiros detalhados sobre despesas ministeriais funcionou como ferramenta primordial do controle tradicional. Argumentos de que estes controles eram ilusórios são provavelmente justificáveis, especialmente porque eles não colaboravam na gestão de recursos (Wilenski, 1986: 231). No entanto, os controles centrais tradicionais permitiam aos guardiões limitar os usos e direções do dinheiro público e orientavam o fluxo de gastos públicos na economia. Nos sistemas delegados de gestão financeira, os guardiões não estão desprovidos de estratégias de controle orçamentário (e poderiam sempre pedir de volta alguns controles detalhados, se assim o desejassem). Em vez disso, suas ferramentas preferidas estão direcionadas para questões de controle de despesas agregadas, e desta maneira constituem uma mudança no foco das políticas orçamentárias de guardian-spender, fora do controle sobre como as agências gastam dinheiro.

Além disso, a delegação da gestão financeira impõe responsabilidade aos próprios gastadores para desempenhar funções de racionamento. Wildavsky mostrou que, no sistema orçamentário tradicional, os gastadores e os guardiões desempenhavam funções especializadas, e que um conjunto de atores podia "empurrar", porque o outro iria "empurrar de volta". Em contraste, o sistema de gestão financeira, previsto pela $N P M$, reduz o grau de especialização nas funções orçamentárias e as forças contrárias equivalentes nas negociações orçamentárias. Os administradores de programa, chefes de departamento e ministros de linha — aqueles atores orçamentários tradicionalmente classificados de gastadores — são solicitados a realizar a função da guarda dentro de suas próprias áreas de responsabilidade financeira (sejam classificados como envelopes, pastas, programas, ou centros de produto, por exemplo). No modelo tradicional, os gastadores fizeram demandas aos guardiões ou procuraram proteger seus programas contra cortes iminentes. Em um sistema orçamentário delegado, as agências gastadoras devem assumir a responsabilidade pela alocação de financiamento disponível para políticas novas e políticas em curso, pela identificação das áreas de restrições de despesas e pela realocação de fundos existentes. Neste sistema, o conflito orçamentário está localizado em áreas específicas de despesas, e é operacionalizado por um grupo de atores que seriam, tradicionalmente, classificados de gastadores.

A introdução de novos modelos de prestação de serviços tem o potencial de enfraquecer a base institucional sobre a qual os gastadores são definidos. A lógica que define o comportamento deles, no modelo de Wildavsky (e seu valor e legitimidade nas negociações orçamentárias), repousa, em grande parte, em seu papel como advogados e especialistas em áreas específicas da política. As informações trocadas entre setores 
da política e setores operacionais, nos ministérios gastadores, produziram uma expertise política detalhada que era indisponível às agências orçamentárias no centro do governo. Ademais, os prestadores de serviços operavam na conexão entre o governo e o público, e assim atuavam como um conduto fornecendo realimentação vital para os debates políticos. Retirando as funções de prestação de serviços dos ministérios gastadores, as reformas da NPM desvalorizam os "argumentos da expertise" pelo ministério remanescente. A prestação de serviços públicos por organizações não-governamentais significa que a expertise política, derivada da prestação de serviços, estará fora do governo e, dessa forma, excluída das considerações orçamentárias de mais alto nível.

Além disso, na medida em que as reformas orçamentárias da NPM formalizaram procedimentos para controle financeiro, elas reduzem o escopo no qual o comportamento do ator pode construir caminhos para tornar rotineiras as relações de acordos entre eles. Maior formalização e transparência não eliminam por completo as políticas relacionais, mas restringem as oportunidades de acordos. Calendários crescentes, por exemplo, irão projetar custos de depreciação consistentes para até daqui a dez anos, e irão indicar despesas a longo prazo, para as quais as agências terão que fazer provisões. As agências gastadoras conhecerão, agora, com freqüência e com anos de antecedência, suas estimativas firmes de despesas e terão poucas oportunidades para aumentar estes valores - e se espera que elas incorporem novas iniciativas políticas dentro das alocações existentes. Elas aproveitam a flexibilidade para transferir recursos para áreas de maior prioridade ou necessidade, e não precisam da autorização do orçamento central para redistribuir seus recursos. É claro que os gastadores poderiam decidir ou permitir a si próprios tornarem-se independentes para tomar decisões e não condescender com essas exigências formais. Em tais circunstâncias, a autorização para operar com poder discricionário delegado tende a ser removida ou severamente cortada (a agência perdendo vários benefícios internos), ou outras penalidades adicionais podem ser impostas às agências recalcitrantes (por exemplo, cobranças adicionais, se incorrerem em "dívida" ou em qualquer tipo de "gastos a mais", podem ser deduzidas de suas estimativas para o próximo ano — como um "empréstimo"). Uma indicação da mudança na lógica de racionamento é a de que as agências gastadoras que conseguem declarar um "dividendo" de volta para o governo (um excedente sobre seus custos) são passíveis de serem recompensadas com novas iniciativas políticas sendo consideradas pelo governo. Paradoxalmente, os melhores agentes de racionamento podem ser as agências que têm maior potencial de crescimento. As reformas exigidas para estabelecer uma separação entre as funções políticas e operacionais do governo complicam as políticas orçamentárias ainda mais, 
introduzindo potencial para uma relação orçamentária de três vias. As

agências centrais atuam como diretor; os ministérios de linha tornam-se agentes de política; e a organização contratada para oferecer serviços governamentais torna-se o agente prestador. Além disso, em alguns programas, os diversos agentes de política podem estar envolvidos com centenas de agentes prestadores. Isto, claramente, não está de acordo com a simples dicotomia sugerida no modelo de guardian-spender. $\mathrm{O}$ aumento do número de provedores de serviços fragmenta o processo orçamentário: isto tende a resultar em negociações mais bilaterais e em relacionamentos temporários. Essa situação se torna especialmente problemática se os provedores de serviços são incluídos nos processos orçamentários. Uma das conveniências do sistema anterior era a de que um ou dois guardiões tratavam com um grupo relativamente pequeno e constante de gastadores. Este ambiente encorajava os relacionamentos estáveis e a "heurística decisória" a que se referia Wildavsky. Em um ambiente mais complexo e fragmentado da $N P M$, estas ferramentas de tomada de decisão orçamentárias se tornarão mais difíceis de serem desenvolvidas, e menos confiáveis.

As decisões sobre quem irá assumir a responsabilidade de renegociar os contratos de prestação de serviços têm uma relação direta nas políticas orçamentárias. A agência central ou as agências de políticas irão renegociar os contratos? Será que os níveis de financiamento para estes contratos serão renegociados entre a agência central e as agências políticas, ou entre o agente político e o prestador de serviços? Como serão estabelecidos os preços e quais pontos de nivelamento serão usados? Se as agências centrais assumirem o papel de "investidor estratégico", então elas absorverão a responsabilidade tanto para gerar pedidos para a bolsa pública (como investidor/comprador) quanto para racionar os recursos disponíveis entre estes pedidos (como guardião) - em outras palavras, elas realizam as funções de racionar e de pedir. Embora estas duas funções não sejam necessariamente contraditórias, elas realmente fogem do sistema de classificação oferecido no modelo de guardian-spender. Se os agentes de política restantes nos ministérios gastadores assumirem a responsabilidade para renegociar contratos, será que eles se comportaram como guardiões do erário público ou como advogados daqueles que são afetados pelos resultados de suas políticas e programas? Embora possamos arriscar respostas a estas perguntas com base na teoria, é necessário muito mais pesquisa, bem como aprender as lições da experiência prática. 


\section{A avaliação do impacto da $N P M$ sobre as políticas orçamentárias}

A confiança generalizada nas reformas da $N P M$ reforça a posição dos guardiões nas políticas orçamentárias. Algumas reformas eliminam as ferramentas tradicionais da guarda - controles rígidos sobre dados detalhados, por exemplo, mas, em geral, elas são substituídas por um conjunto mais amplo de estratégias que ampliam a caixa de ferramentas dos guardiões, especialmente em termos de controle de despesas agregadas. Ao mesmo tempo, a NPM reduz a capacidade e a legitimidade de várias estratégias adotadas pelos gastadores, e tem o potencial para enfraquecer sua base institucional. Vários atores orçamentários, que seriam classificados de gastadores em uma análise institucional de seu papel orçamentário, estão sendo encorajados a comportar-se como guardiões orçamentários. Conseqüentemente, um programa extensivo de reforma da NPM tende a mudar o equilíbrio de poder, dentro do sistema orçamentário, em favor dos guardiões, e deveria, portanto, facilitar o aumento de capacidade para impor uma disciplina orçamentária.

Desta forma, a simples dicotomia entre os guardians-spenders é difícil de ser sustentada. Estão surgindo relacionamentos mais complexos (por exemplo, diretor de três vias, agência de política e agente de serviços nos termos da separação comprador/provedor) nos quais não fica claro qual o papel de cada um no processo orçamentário. Ademais, várias das reformas da $N P M$ deliberadamente eliminam a fronteira entre o papel institucional e a função orçamentária. Cada vez mais, os guardiões serão solicitados a realizar tanto as funções de racionamento quanto de reivindicações, sendo exigido dos gastadores que façam tanto uma coisa quanto outra. Em outras palavras, as novas funções orçamentárias não se alinham, necessariamente, com os papéis institucionais tradicionais.

Além disso, as reformas da NPM têm potencial para redefinir as áreas de conflito orçamentário, assim como as áreas de entendimento. Os guardiões são capazes de fazer mais, unilateralmente (por exemplo, negociando contratos e estabelecendo metas de despesas agregadas), mas eles devem lidar com uma comunidade mais fragmentada (e talvez menos estável) de gastadores (especialmente se os prestadores de serviços forem incluídos no processo orçamentário). O conflito tende a ser descentralizado, fora das agências orçamentárias centrais — com antigos gastadores atuando como guardiões sobre alocações de despesas detalhadas. Orçamentos plurianuais tendem a resultar em conflitos orçamentários mais intensos, apesar de as negociações ocorrerem com menor freqüência. O impacto, a mais longo prazo, das reformas da NPM sobre as políticas orçamentárias não ficará evidente até que padrões regularizados possam ser identificados e que relacionamentos mais complexos fiquem mais claros. 
O impacto das políticas orçamentárias em jurisdições específicas

irá variar de acordo com diversos fatores, não sendo, dentre eles, menos importantes, as reformas da NPM já implementadas, bem como o projeto detalhado dessas reformas. Como foi mencionado nas seções anteriores, cada nação tem perseguido a agenda de reforma da NPM com diferentes graus de vigor, contra antecedentes institucionais e históricos diferentes, e com um nível considerável de variação nacional. Determinar se nossas descobertas iniciais são aplicáveis em qualquer país ou a extensão na qual elas podem ser generalizadas irá exigir, consideravelmente, mais pesquisas.

\section{Os guardians-spenders de Wildavsky ainda são relevantes?}

O que nossa pesquisa sugere para a contínua relevância dos guardians-spenders de Wildavsky? Primeiramente, ela demonstra a contínua relevância desta estrutura. Ela proporciona um quadro analítico proveitoso para estudar as reformas orçamentárias quase 40 anos após seu desenvolvimento. Ela mostra que a estrutura guardian-spender proporciona uma metodologia de diagnóstico para avaliar o impacto da $N P M$ nas relações entre atores orçamentários, e um meio de identificar desequilíbrios potenciais no sistema orçamentário de um país.

No entanto, o acima exposto sugere que a base de definição das políticas orçamentárias, no modelo de Wildavsky, está sendo questionada pelas reformas da NPM. A definição de Wildavsky dos papéis orçamentários sempre foi inexata, mas nós sabemos que ela concordava com ambas as posições institucionais dos atores orçamentários, e podia variar de acordo com os sistemas orçamentários. A extensão dessas classificações permitia que as análises das políticas orçamentárias permanecessem sólidas, e criavam uma equivalência funcional, em vez de institucional, no cerne de qualquer análise comparativa.

Sugerimos uma classificação expandida que faz diferenciação entre os papéis institucionais dos atores orçamentários individuais (Wildavsky), e a(s) função(ões) que eles desempenham nas negociações orçamentárias (Schick, 1990;1994). Fazer distinção entre papel e função deveria facilitar a análise das políticas orçamentárias em um certo número de níveis. Ela proporciona maior flexibilidade na classificação da posição dos atores no processo orçamentário. Ela sugere que alguns atores podem realizar múltiplas funções em um mesmo estágio do processo orçamentário (por exemplo, uma agência central do orçamento pode simultaneamente requerer e racionar durante a formulação do orçamento); ou realizar diferentes funções em vários estágios da tomada de decisões do orçamento (requerer durante a formulação do orçamento, mas racionar durante a 
implementação do ano orçamentário). Ela também permite a possibilidade de que, embora o papel institucional do ator permaneça constante, suas funções orçamentárias possam mudar com o tempo. Finalmente, a distinção permite a identificação da assimetria entre o papel institucional dos atores orçamentários e as funções que eles são chamados a desempenhar no processo orçamentário. Embora uma tal assimetria possa ser a consequiência deliberada da reforma (como na $N P M$ ), nós acreditamos que é vital poder identificar qualquer possível disjunção entre a função que um servidor público é chamado a realizar e o incentivo ou cultura associados a sua posição institucional.

\section{Conclusões: a NPM e os problemas de excedentes orçamentários}

As reformas da NPM tiveram ascendência durante um contexto histórico específico, no qual os governos lutavam com problemas de crescimento restritivo nos gastos governamentais, reduzindo os déficits orçamentários e cortando as dívidas (Hood, 1991; Wright, 1979; Hood e Wright, 1981). Este caminho para uma disciplina fiscal criou um ambiente que requeria novos métodos orçamentários que fortificassem os guardiões, impusessem limites fiscais e modificassem as estruturas de incentivo, moldando o comportamento burocrático. Este contexto ajustou-se claramente com a ênfase do paradigma da $N P M$ sobre a "economia e a parcimônia" (Hood, 1991). As reformas da NPM contribuíram na busca de disciplina fiscal e de restrição orçamentária, dando poderes aos guardiões do erário público e procurando enraizar os valores da "linha de base". Em outras palavras, ao transferir o equilíbrio do poder no sistema orçamentário, as reformas da $N P M$ contribuíram para capacitar os governos a orçar em uma era de restrições.

Mais recentemente, contudo, governos do mundo todo têm registrado excedentes orçamentários, ano após ano, e níveis de dívida significativamente mais baixos (alguns dos quais podem estar diretamente relacionados às reformas da $N P M$ ). Este desenvolvimento leva-nos a indagar se os mecanismos que ajudaram a restringir os gastos são apropriados ou eficazes em uma era de excedentes. $\mathrm{O}$ foco dos debates orçamentários começou a se transferir de como cortar as dívidas e os déficits de governo, para como gerenciar e o que fazer com os excedentes orçamentários (Posner e Gordon, 1999; OCDE, 1999). Qualquer relaxamento no ímpeto da restrição imediata de despesas tende a mudar o relacionamento entre os atores orçamentários, por:

- desafiar ou desgastar a posição estratégica ganha pelos guardiões por meio de controles de despesas agregadas; 
- requerer decisões mais voltadas para programas prioritários (de alocações ou de racionamento) a serem empreendidas em uma base política; e

- legitimar os argumentos gastadores para inclusão mais ampla no processo orçamentário.

Paradoxalmente, uma vez tendo produzido excedentes, a posição dominante adquirida pelos guardiões será questionada e sua habilidade para controlar despesas agregadas tenderá a desgastar-se. Novas prioridades podem ser financeiramente absorvidas de forma ostensiva e os governos podem ser forçados, por pressão política, a relaxar seus padrões anteriores de racionamento severo. Até aumentos relativamente pequenos (e politicamente dirigidos) nos gastos logo consumirão os poucos excedentes orçamentários registrados até hoje.

A Tabela 2 sugere algumas opções de política orçamentária disponíveis para os governos, nesse novo ambiente orçamentário, e suas implicações para a política orçamentária. Embora gastar seja a alternativa mais óbvia para poupar os excedentes orçamentários anuais, os gastos podem ser direcionados para diferentes estratégias, cada uma das quais tem implicações para a capacidade fiscal futura, bem como para a política orçamentária do governo. Nenhuma opção é mutuamente exclusiva e alguns países estão adotando mais de uma alternativa. Ainda assim, a pesquisa constante de nossa tabela sugere que cada opção produz dinâmicas políticas bem diferentes e impõe diferentes exigências aos atores orçamentários. O cumprimento das opções desejadas de um governo em particular tende a exigir mudanças adicionais no sistema orçamentário e pode transferir o equilíbrio do poder nas políticas orçamentárias.

Levando em consideração as conclusões de nossa pesquisa, verificase que o novo ambiente orçamentário irá revelar uma redução na capacidade daqueles atores orçamentários que operam como requerentesgastadores. Seguindo a lógica de Schick e Wildavsky, esperamos que as dificuldades em se orçar, neste novo "ambiente de excedentes", irão resultar em orçamentação improvisada ou ad hoc, ou produzir ímpetos renovados para reformas orçamentárias que compensem qualquer desequilíbrio entre os gastadores e os guardiões do orçamento. 


\section{Tabela 2: Estratégias e opções para excedentes orçamentários continuados. Implicações potenciais das opções de estratégia}

\section{Visa acumular o excedente - supremacia institucional dos guardiões em projetar limites agregados rígidos.}

1.1. Mantém como reserva líquida - uma opção conservadora e inativa, na qual os excedentes são retidos como uma base de crédito financeiro cumulativo do governo, mas não usados de outra forma. Os ativos, na reserva líquida, são creditados contra a dívida bruta para calcular a dívida líquida inferior. Existem custos prévios implícitos de interesse, se os ativos não forem usados, e uma erosão potencial do valor da reserva pela inflação. Esta opção não é considerada, normalmente, como preferível nas economias modernas.

1.2. Investir ou emprestar - excedentes podem ser acumulados para empréstimos aos setores público e privado. $\mathrm{O}$ governo age como um banqueiro, potencialmente usando sua habilidade para pedir emprestado a taxas mais baixas que os tomadores de empréstimo comerciais. Esta opção pode causar impacto nos mercados de capital privado e pode explorar os contribuintes. A base de crédito financeiro também é calculada contra a dívida bruta para baixar a dívida líquida. No entanto, o tamanho da base de crédito e sua fácil liquidez podem produzir pressão para concessões únicas aos ministérios gastadores. Esta opção tem poucas chances de funcionar indefinidamente. O propósito de acumular excedentes não será, necessariamente, aparente. Talvez essa opção só seja conveniente para economias simples, ou nas quais os governos possam extrair rendas de uma fonte.

2. Visa eliminar a dívida pública — gastadores restringidos pela estratégia de longo prazo dos guardiões.

2.1. Reduzir os níveis do principal da dívida - o principal da dívida é progressivamente eliminado pelo pagamento automático, por parte do governo, sempre que aparece um excedente. Esta é uma opção conservadora e financeiramente livre de risco. Ela é mais apropriada quando os níveis de dívida e as taxas de juros são altos. Pode ser usada para reduzir o conflito entre os guardians-spenders, se os fundos adicionais forem liberados na medida em que o pagamento dos juros for exigido. Os excedentes podem ser disfarçados ou tecnicamente evitados calculando-se uma quantia para a eliminação da dívida dentro do orçamento anual, como um item de despesa. Alternativamente, o excedente pode ser declarado e a dívida paga inteiramente após o ano orçamentário. Este mecanismo está disponível para economias complexas, mas somente a médio prazo, e sujeito ao ciclo econômico.

3. Visa realocar o excedente para outros fins estratégicos - pode necessitar cada vez mais informações por parte dos gastadores.

3.1. Redução de impostos - a redução de impostos pode ser usada como um incentivo eleitoral, ou para reduzir o tamanho do governo. Decisões políticas/econômicas podem ser feitas com propósitos, natureza, proporção e periodicidade intencionais de redução de impostos. Contudo, as mudanças 
na tributação terão impactos macroeconômicos expansionistas ou contraditórios incertos, dependendo da reação dos setores corporativo e consumidor (i.e., o equilíbrio entre poupança privada e gastos privados). Também haverá maior pressão sobre os orçamentos, na medida em que os excedentes diminuírem. Conseqüentemente, esta opção não está livre de risco em termos eleitorais ou em termos econômicos. Note-se que as reduções de impostos podem ser ilusórias, em decorrência da combinação de impostos ou da incidência de impostos sucessivos em condições de inflação.

3.2. Aumentar as despesas nos itens recorrentes incluindo transferências o aumento das despesas pode ser apresentado como um dividendo de parcimônias passadas. Os governos podem voltar a priorizar seus gastos e a promessa de despesas futuras pode ser eleitoralmente atraente (e constituir um incentivo para as decisões do governo quanto a cortes de despesas correntes). Haverá uma pressão imediata sobre o tamanho do excedente e, talvez, uma pressão sobre a manutenção de novas alocações recorrentes. Gastos adicionais irão aumentar o tamanho do governo. Irão, também, causar impactos macroeconômicos expansionistas ou não, dependendo do uso dos fundos e das reações do mercado. Apesar de parecer benevolente, a opção coloca riscos eleitorais e econômicos. Ela supõe capacidade para racionar pedidos de novas despesas em benefícios políticos versus perda do critério de excedente, senão o modelo anterior é restabelecido.

3.3. Aumentar as despesas como um investimento estratégico - as agências guardiãs proporcionam incentivos para capacitar as agências gastadoras e prestadoras de serviços a "financiarem-se" e reduzir sua dependência da receita global (i.e., aumentar sua habilidade futura de fazer despesas para investimentos geradores de renda e/ou reduzir trabalho e outras eficiências cortadoras de gastos). Na Austrália, os "acordos de recursos" proporcionaram recursos adicionais para reduzir a dependência de longo prazo sobre o orçamento de recursos. Porém, as agências gastadoras têm incentivo e habilidade para disfarçar os custos recorrentes como despesas de investimento, se o acordo de recursos que monitora sua operação não é eficaz.

Vários países da OCDE têm mostrado capacidade notável para impor restrições fiscais e criar excedentes orçamentários. O sucesso tem sido atingido por uma combinação de vontade política, burocracia disciplinada e aceitação eleitoral. De forma questionável, alguns governos têm conseguido gerenciar este processo, enquanto se dedicam a questões de igualdade de sacrifício e proporcionam formas parciais de compensação com medidas austeras. Esta disciplina, contudo, tem produzido, em troca, uma ortodoxia emergente que vê os excedentes orçamentários como o objetivo principal da política do governo, e não como, apenas, um de seus resultados. Tais excedentes são obtidos para aumentar a confiança dos mercados financeiros na performance do governo. A maneira pela qual os governos gerenciam e distribuem seus excedentes não irá apenas ter um impacto sobre os vencedores e os perdedores na sociedade, mas, com freqüência, irá determinar a sobrevivência do próprio governo. Para permanecer no 
poder, os governos têm mostrado que estão cada vez mais preparados para entrincheirarem-se em estratégias fiscais restritivas, que irão, adicionalmente, restringir a sua discricionariedade política. "Continuar a gerenciar menos" pode, em breve, transformar-se em novo lema do governo.

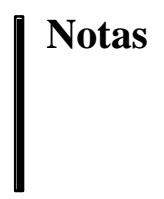

* Artigo disponível em inglês, no site www.willamette.org, sob o título New Public Management and the Politics of Government Budgeting. Autorizado por Fred Thompson, professor da Geo. H. Atkinson Graduate School of Management, Willamet University, Salem, Oregon.

${ }^{1} \mathrm{O}$ jogo simples de dois protagonistas representado na dicotomia de guardian-spender de Wildavsky possibilitou aos teóricos de escolha coletiva analisar as políticas orçamentárias usando um dilema de dois jogadores prisioneiros, que de maneira bem ampla, concorda com o modelo "patrocinador de escritório" do processo orçamentário de Niskanen. A principal diferença entre estes dois modelos resulta dos modelos respectivos de comportamento humano que os embasam (ver Wildavsky, 1974: 189-94; em seus comentários sobre a "racionalidade política").

${ }^{2}$ Wildavsky usou os termos guardian-spender de forma quase livre em suas obras. Os participantes são, variavelmente, classificados de "guardiões", "revisores", "cortadores de despesas" ou "poupadores", e também como "advogados" e "gastadores". Em seu trabalho de cooperação com Davis et al., (1966), Wildavsky dispensou completamente a diferenciação entre estas categorias.

\section{|| Referências bibliográficas}

Aitken, J. (1995), "Resource Accounting — Much More Than Just A Technical Change". Chief Secretary to HM Treasury. Speaking to the Social March Foundation, London, 22 february.

Aucoin, P. (1990), “Administrative Reform in Public Management: Paradigms, Principles, Paradoxes and Pendulums". Government, 3, pp. 115-37.

Australian Public Service Board andDepartmentof Finance. (1984), FinancialManagement Improvement Program. Canberra: AGPS.

Blair, T. (1999), "Modernizing Government". Presentation to Parliament by the Primer Minister and the Minister for the Cabinet Office, CM 4310, march. London: HMSO.

Boston, J.; Martin, J.; Pallot, P.; Walsh, P. (eds.). (1991), Reshaping the State: New Zealand's Bureaucratic Revolution. Auckland: Oxford University Press. 
Oxford University Press.

Caiden, N. (1998), “A New Generation of Budget Reform”, in Peters, B. G. and Savoie, D. J. (eds.), Taking Stock: Assessing Public Sector Reforms. Montreal: McGill-Queens University Press, pp. 252-284.

CAiden, N.; Wildavsky, A. (1974), Planning and Budgeting in Poor Countries. New York: Wiley and Sons.

Campos, J. E.; Pradhan, S. (1997), "Evaluating Public Expenditure Management Systems: An Experimental Methodology with an Application to the Australia and New Zealand Reforms". Journal of Policy Analysis and Management, 16/3, pp. 423-225.

Dawkins, J. S. (1984), Budget Reform: A Statement of the Government's Achievements and Intentions in Reforming Australian Governmental Financial Administration.Canberra: AGPS.

Dunleavy, P.; Hood, C. (1994), "From Old Public Administration to New Public Management". Public Money and Management, 1/3, pp. 9-16.

Ewart, B.; Boston, J. (1993), "The Separation of Policy Advice from Operations: the Case of Defense Restructuring in New Zealand". Australian Journal of Public Administration, 52/2, pp. 122-137.

Forster, J.; Wanna, J. (eds.). (1990), Budgetary Management And Control: The Public Sector In Australasia. South Melbourne: MacMillan.

Frederickson, H. G. (1996), "Comparing the Reinventing Government Movement with the New Public Administration”. Public Administration Review, 56/3, pp. 263-70.

GoRe, A. (1993), Creating a Government that Works Better and Costs Less: The Report of the National Performance Review. Washington D.C.: National Performance Review.

Gray, A.; Jenkins, B. (1995), "From Public Administration to Public Management: Reassessing a Revolution?”. Public Administration, 73/1, pp. 75-100.

Green, F.; Thompson, F. (1999), "Organizational Process Models of Budgeting". Unpublished manuscript, Salem, Oregon: Atkinson Graduate School of Management, Willamette University.

Heclo, H.; Wildavsky, A. (1975), The Private Government of Public Money. London: Macmillan.

Hood, C. (1987), "British Administrative Trends and The Public Choice Revolution", in Lane, J. E. (ed.), Bureaucracy and Public Choice. London: Sage, pp. 146-170. . (1991), “A Public Management for All Seasons?”. Public Administration, 69/1, pp. 3-19.

. (1995), "The New Public Management", in: The 1990s: Variations on a Theme, Accounting Organizations and Society, 20: 2/3, pp. 93-109. EDITOR(S)? (1997), "Which Contract State? Four Perspectives on Over-

Outsourcing Public Services". Australian Journal of Public Administration, 56/3.

Hughes, O. E. (1994), Public Management and Administration: An Introduction. New York: St. Martin's Press.

Joint Committee on Public Administration. (1989), "Submission by the Department of the Prime Minister and Cabinet". Inquiry into the Department of Finance. Parliament of Australia: S10-64.

Jones, L. R.; McCAFFery, J. L. (1994), "Budgeting According to Aaron Wildavsky: A Bibliographic Essay". Public Budgeting and Finance, 14/1, pp. 16-43.

Keating, M. (1989), "Quo Vadis: Challenges of Public Administration". Address to Royal Australia Institute of Public Administration, Perth, 12 april. . (1998), Personal Interview. Brisbane: Australia.

Keating, M.; Holmes, M. (1990), "Australia's Budgetary and Financial Management Reforms". Governance, 3/2, pp. 168-85. 
Kemp, P. (1990), "Next Steps for the British Civil Service". Governance, 3/2. pp. 168-96.

KetTL, D. F. (1997), "The Global Revolution in Public Management: Driving Themes, Missing Links". Journal of Policy Analysis and Management, 16/3, pp. 446-62.

Keraudren, P.; Van Mierlo, H. (1998), "Theories of Public Management Reform and Their Practical Application”, in Verhejen, T.; Coombes, D.; Elgar, E. (eds.), Innovations in Public Management: Perspectives from East and West Europe. Cheltenham, pp.39-56.

Management Advisory Board. (1997), Beyond Bean Counting: Effective Financial Management in the APS - 1998 and Beyond. Canberra: Australian Government Printing Office.

M Liburn, A. (1998), "Public Services for the Future: Modernization, Reform Accountability, Comprehensive Spending Review: Public Service Agreements 1999-2002". Presentation to the Parliament by the Chief Secretary to The Treasury. Cm 4181, december.

Moon, J. (1999), “The Australian Public Sector and New Governance”. Australian Journal of Public Administration, 58/2, pp. 112-20.

New Zealand Treasury. (1987), "Government Management." Brief to the Incoming Government. Volume one, Wellington: Government Printing Office.

OECD. (1999), Budgeting in a Surplus Environment. Paris: OECD. . (1997), Modern Budgeting. Paris: OECD.

. (1995), Governance in Transition: Public Management Reforms in OECD Countries. Paris: OECD.

Osborne, D.; Gaebler, T. (1992), "Reinventing Government: How the Entrepreneurial Spirit is Transforming the Public Sector". Reading MA: Addison Wesley.

Pallot, J. (1998), "Newer than New Public Management: Financial Management and Collective Strategizing in New Zealand". International Public Management Journal, 1(1).

Peters, B. G.; SAvole, D. J. (eds.). (1998), Taking Stock: Assessing Public Sector Reforms. Montreal: McGill-Queens University Press.

Pollitt, C. (1998), "Managerialism Revisited", in Peters, B. G. and Savoie, D. J. (eds.) Taking Stock: Assessing Public Reforms. Montreal: McGill-Queens University Press, pp. 45-77.

. (1993), Managerialism and the Public Services: Cuts or Cultural Change in the 1990s? $2^{\text {nd }}$ edition, Oxford, Blackwell.

Portillo, M. (1994), "Transforming the Public Sector". Chief Secretary to HM Treasury Speaking to The Oxford Desregulation Seminar, 7 january, London.

Prime Minister and Minister for The Cabinet Office. (1999), Modernizing Government. London: HMPO.

Premchand, A. (1998), "Umbrella Themes Obscure Real Problems: an Appraisal of Recent Efforts to Improve Financial Management". Public Budgeting and Finance, 18/2, pp. $72-87$.

RuBin, I. (1990), The Politics of Public Budgeting: Getting and Spending, Borrowing and Balancing. New Lersey: Chatham House.

Savole, A. (1990), The Politics of Budgeting in Canada. Toronto: University of Toronto Press.

Sсніск, A. (1990), The Capacity to Budget. Washington D.C.: The Urban Institute Press. . (1994), "From the Old Politics of Budgeting to the New". Public Budgeting and Finance, 14/1, pp. 135-44. . (1997), The Changing Role of the Central Budget Office. Paris: OECD.

Schawrtz, H. M. (1997), "Reinvention and Retrenchment: Lessons from the Application of the New Zealand Model to Alberta, Canada". Journal of Policy Analysis and Management, 16/3, pp. 405-422.

Thompson, F. (1998), "Public Economics and Public Administration", in Rabin, J.; Hildreth, B.; Miller, J. (eds.), Handbook of Public Administration, $2^{\text {nd }}$ edition. New York: Marcel Dekker, pp. 995-1063. 
Verheijen, T.; Coombes, D. (eds.). (1998), Innovations in Public Management: Perspectives from East and West Europe. Cheltenham: Edward Elgar.

Von Hagen, J. (1992), "Budgeting Procedures and Fiscal Performance in the European Communities”. Unpublished manuscript, Bloomington, Indiana: University of Mannheim and Indiana University School of Business.

Wildavsky, A. (1961), "Political Implications of Budgetary Reform”. Public Administration Review, 21/3, pp. 183-90.

. (1974), "The Politics of the Budgetary Process", $2^{\text {nd }}$ edition. Boston: Little, Brown \& Co.

. (1978), "A Budget for All Seasons? Why the Traditional Budget Lasts". Public Administration Review, 6/2, pp. 501-509.

. (1979), How to Limit Government Spending. Berkeley: University of California Press.

. (1986), Budgeting: A Comparative Theory of Budgetary Processes, $2^{\text {nd }}$ edition. New Brunswick: Transaction Books.

. (1988), The New Politics of the Budgetary Process, $4^{\text {th }}$ edition. Illinois: Scott, Foresman and Co.

. (1986), Public Power and Public Administration. Sydney: Hale and Iremonger. 


\section{Resumo \\ Resumen \\ Abstract}

\section{A nova gestão pública e as políticas de programação orçamentária do governo \\ Joanne Kelly e John Wanna}

Neste artigo nós aplicamos a teoria de Wildavsky de guardian-spender para analisar o impacto das reformas da Nova Gestão Pública nas políticas orçamentárias, bem como para testar o contínuo valor explicativo dessa teoria. O estudo tem foco em três objetivos amplos da reforma orçamentária e financeira da New Public Managemnet - NPM; a reformulação dos objetivos e da cultura orçamentária, a centralização dos controles de gastos agregados e o aumento da delegação e de flexibilidade na gestão financeira detalhada.

Nós argumentamos que onde as reformas da NPM têm longo alcance, elas mudam o equillíbrio de poder nas políticas orçamentárias e estabelecem arranjos orçamentários mais complexos do que os sugeridos pelo modelo guardian-spender. Primeiramente, a administração das reformas orçamentárias e financeiras da NPM muda o equilíbrio global de poder dentro do sistema orçamentário em favor dos guardiãos, por : a) aumentar as estratégias disponíveis para os guardiãos; e b) mudar o papel orçamentário dos gastadores e desafiar sua contínua legitimidade como atores orçamentários. Segundo, uma simples dicotomia entre guardiões e gastadores é difícil de se manter, porque: a) a função orçamentária não necessariamente se alinha com o papel institucional e pode mudar ao longo do tempo; e b) estão surgindo relações orçamentárias mais complexas que não pactuam com a divisão guardian-spender. Terceiro, o sistema orçamentário reformulado muda tanto o foco do conflito orçamentário como suas áreas de acordo. As relações orçamentárias parecem ser menos estáveis se os responsáveis pelos serviços contratuais estiverem incluídos no processo; o conflito parece estar descentralizado das agências centrais de orçamento, com antigos gastadores assumindo o papel de guardadores dos gastos totais detalhados. O advento de orçamentos plurianuais (não apenas previsões) pode acirrar conflitos orçamentários, mas os conflitos ocorrerão com menor freqüência. Finalmente, concluímos questionando se um sistema orçamentário "transformado" requer mais emendas quando ocorrem excedentes no orçamento.

\section{La nueva gestión pública y las políticas de programación presupuestaria del gobierno}

\section{Joanne Kelly y John Wanna}

En este artículo nosotros aplicamos la teoría de Wildalsky de guardian-spender para analizar el impacto de las reformas de la Nueva Gestión Pública en las políticas presupuestarias, así como para testar el continuo valor explicativo de esta teoría. El estudio enfoca tres objetivos amplios de la reforma presupuestaria y financiera de la $\mathrm{New}$ Public Management - NPM; la reformulación de los objetivos y de la cultura presupuestaria, la centralización de los controles de los gastos agregados y el aumento de la delegación y de la flexibilidad en la gestión financiera detallada.

Nosotros argumentamos que dónde las reformas de la NPM tienen largo alcance, ellas cambian el equilibrio de poder en las políticas presupuestarias y establecen arreglos presupuestarios más complejos del que los sugeridos por el modelo guardian-spender. Primeramente, la administración de las reformas presupuestarias y financieras de la NPM cambia el equilibrio global de poder dentro del sistema presupuestario en favor de los guardianes, por: a) aumentar la estrategias disponibles para los guardianes; y b) cambiar el papel presupuestario de los gastadores y desafiar su continua legitimidad como actores
Revista do

Serviço

Público

Ano 52

Número 3

Jul-Set 2001

Joanne Kelly é chefe de pesquisa do Expenditures and Management Strategies Sector no Canadá.

John Wanna é professor da Head of School Politics and Public Policy na Austrália. 
presupuestarios. Segundo, una simple dicotomía entre guardianes y gastadores es difícil de mantenerse, por que: a) la función presupuestaria non necesariamente se aliña con el papel institucional y puede cambiar con el tiempo; y b) están surgiendo relaciones presupuestarias más complejas que non pactúan con la división guardian-spender. Tercero, el sistema presupuestario reformulado cambia tanto el foco del conflicto presupuestario como sus áreas de acuerdo. Las relaciones presupuestarias parecen ser menos estables si los responsables por los servicios contratuales estuvieren incluidos en lo proceso; el conflicto parece estar descentralizado de las agencias centrales del presupuesto, com antiguos gastadores asumiendo el papel de guardadores de los gastos totales detallados. El advento de los presupuestos plurianuales (non apenas previsiones) puede acirrar conflictos presupuestarios, pero los conflictos ocurrirán com menor frecuencia. Finalmente, concluimos questionando si un sistema presupuestario transformado requiere más enmiendas cuando ocurren excedentes en el presupuesto.

\section{New public management and the politics of government budgeting}

\section{Joanne Kelly and John Wanna}

In this paper we apply Wildavsky's guardian-spender framework to analyse the impact of New Public Management (NPM) reforms on budgetary politics, and to test the framework's continued explanatory value. The study focuses on three broad objectives of NPM budgetary and financial reform: reformulation of budgetary objectives and culture, centralisation of aggregate expenditure controls, and increased devolution and flexibility in detailed financial management.

We argue that where NPM reforms are far-reaching they shift the balance of power in budgetary politics, and estabilish more complex budgetary arrangements than suggested by the guardian-spender model. First, NPM budgetary and financial management reforms change the overall balance of power within the budget system in favour of guardians by a) increasing the strategies available to guardians and $b$ ) changing spenders' budgetary role and challenging their continued legitimacy as budget actors. Second, a simple dichotomy between guardians and spenders is difficult to sustain because a) budgetary function does not necessarily align with institutional role and can change over time; and b) more complex budgetary relationships are emerging that do not accord with the guardian-spender split. Third, the reformulated budgetary system potentially shifts the focus of budgetary conflict and the areas of budgetary agreement. Budgetary relationships are likely to be less stable if contratual service deliverers are included in the process; conflict is likely to be decentralised away from central budget agencies with former spenders assuming a guardianship role over detailed expenditure totals. The advent of multi-year budgets (not just forecasts) may intensify budgetary conflicts, but see them occuring less often. Finally, we conclude by asking whether the "transformed" budgetary system is likely to require further amendment under conditions of surplus budgeting. 